\title{
Pathway for recovery of photo-degraded polymer solar cells by post degradation thermal anneal
}

J Bhattacharya $a$, P H Joshi ${ }_{a}$, R Biswas $a, b, c, \underline{\text { V L Dalal }} \underline{\underline{a}, \underline{b}}$

\begin{abstract}
:-
The photo-degradation of polymer solar cells is a critical challenge preventing its commercial deployment. We experimentally fabricate organic solar cells and characterize their degradation under solar simulators in an environmental chamber under nitrogen flow, without exposure to oxygen and moisture. We have developed a thermally stable inverted organic solar cell architecture in which light induced degradation of device characteristics can be reversibly annealed to the pristine values. The stable inverted cells utilized $\mathrm{MoO}_{\mathrm{x}}$ layers that are thermally treated immediately after their deposition on the organic layer, and before metal cathode deposition. Organic solar cells that are photo-degraded in the presence of oxygen, however show irreversible degradation that cannot be thermally recovered. The decrease of organic solar cell characteristics correlates with increases in mid-gap electronic states, measured using capacitance spectroscopy and dark current. It is likely the photo-induced defect states caused by local $\mathrm{H}$ motion from the alkyl chains to the aromatic backbone, can be reversibly annealed at elevated temperatures after photo-degradation. Our results provide a pathway for improving the stability of organic photovoltaics.
\end{abstract}

Keywords: Organic Solar Cells, Photo Degradation, Shockley Read Hall recombination, Defect Density, Capacitance spectroscopy, Thermal Stability, Stability

\section{Introduction}

Organic solar cells have attracted broad scientific interest due to their simple processing techniques, flexibility in tuning bandgap, and their ability to be deposited on curved substrates. Recent advances have resulted in organic solar cell (OSC) efficiencies near $11.5 \%$ for typical single junction configuration [1], and $\sim 13.5 \%$ for multi-junction cells [2]. However degradation remains a critical issue which needs to be understood, and minimized, for a pathway to commercialization.

A large body of work has been performed on extrinsic degradation caused by ingress of oxygen and moisture in the solar cell. Krebs et al [3] reported degradation in ambient moisture, where moisture intrudes the cell stack through the aluminum cathode layer leading to degradation of the constituent interfaces. Kawano et al [4] proposed that PEDOT:PSS based hole transport layer reacts with ambient moisture and oxygen leading to the formation of a charge injection barrier at HTL-active layer interface causing degradation in charge collection. Wang et al [5] proposed the formation of an $\mathrm{Al}_{2} \mathrm{O}_{3}$ barrier at the cathode side of the device due to the reaction between the Al cathode and ambient oxygen/moisture, hindering efficient electron collection. Resse et al [6] also proposed that metal cathodes were a source of 
the degradation of organic cells. For simplicity, all these above degradation findings are grouped as extrinsic degradation.

In seminal work, Jorgenson et al [7] detailed the photo-chemical reaction of photo-excited polymers with oxygen leading to the breaking of polymer backbone. This occurs because of the exchange of electron from an excited electronic state of the polymer to the oxygen. There are studies detailing the oxygen induced degradation in polymer based OSCs [8-13]. It was hypothesized by Kawano et al [4] that PSS (poly 4-styrene sulfonate) groups of PEDOT: PSS layer tend to diffuse into active layer and photochemically react with polymer resulting in active layer degradation. Guerror et el [10] proposed that molecular oxygen can form polymer-oxygen $\mathrm{O}_{2}$ complex and the formation of such complexes were directly linked to the drop in photo-current and voltage. Rivaton et al [14] concluded that oxygen induced photo degradation is due to the reduction in polymer conjugation length and the photo-chemical reaction was termed photo-bleaching or photo-oxidation. Device encapsulation can reduce such extrinsic degradation.

There are also various studies of intrinsic degradation caused by exposure to light itself, in the absence of moisture and oxygen. Intrinsic degradation cannot be reduced by encapsulation alone. Oxygen may be an accelerator in photo-bleaching, but even in its absence, light could cause considerable damage to the performance of organic based solar cells. Street et al $[15,16]$ and Bhattacharya et al [17] and recently Tamai et al [18] reported that even in the absence of ambient oxygen and moisture, prolonged light illumination can degrade the efficiency of the organic solar cells by creating mid-gap electronic states, resulting in increased rate of trap-assisted recombination, and lower open circuit voltage and short circuit current due to the deterioration of the charge transport of photo-generated charge carriers. The origin of charge traps was discussed with ESR measurements and density functional theory. The same work demonstrated the completed recovery of performance of photo-degraded cell upon post-degradation thermal annealing [18]. Furthermore photo-degraded solar cells that were thermally annealed, showed reductions in sub-gap photo-absorption indicative of the reduction in mid-gap defect density [15]. Previous studies by Toshihiro et al [19] showed a recovery of OPV performance upon post degradation thermal treatment. The author attributed photo degradation to charge accumulation at cathode-organic interface as an interpretation of performance recovery. Katz et al also reported the recovery of OPV performances after concentrated light exposure and attributed the change of the performance to anode HTL series resistance caused by $\mathrm{O}_{2}$ desorption/adsorption respectively [20-22]. Other groups also reported the impact of thermal treatment on the performance of degraded cells [23, 24]. It is possible to prevent the interaction of atmospheric moisture/oxygen with the cell stack by encapsulation materials. However this does not protect the solar cell when the active material itself is unstable under light. So understanding the pathway of photo degradation becomes critical for developing pathways to stabilize OSCs.

In this paper, we fabricate a P3HT (poly 3-hexylthiophene-2,5-diyl ) based bulk heterojunction solar cell with an inverted $n-i-p$ architecture with specialized processing sequence containing $\mathrm{MoO}_{\mathrm{x}}$ holetransport layer. We characterize the degradation of the solar cell under light illumination in a nitrogen filled atmosphere. We then show that, it is possible to completely recover the solar cell efficiency and device characteristics that were photo-degraded by thermal annealing. Detailed measurements of mid- gap defect states by both capacitance spectroscopy and dark current are presented to demonstrate the complete recovery of the performance of the solar cell. In contrast, we find that the p-i-n cells cannot be thermally annealed after light degradation because of metal cathode instability due to temperature treatment. The 
mechanisms underlying degradation under light illumination and thermal recovery is discussed using these measurements.

\section{Experimental Details}

Organic solar cells (OSCs) were fabricated from regio-regular P3HT (Sigma Aldrich / Average Mw 54,000-75,000 and PDI $\leq 2.5$ (product code- 698997) with $99.995 \%$ trace metal basis) based donor and $\mathrm{PC}_{60} \mathrm{BM}$ (Nano-C) in both regular (p-i-n) and inverted (n-i-p) type bulk-heterojunction architectures. We have obtained ITO-coated glass substrates with sheet resistance $\sigma=16 \Omega / \square$ (Colorado concepts). To serve as a hole transport layer in p-i-n cells, a $30 \mathrm{~nm}$ PEDOT:PSS is deposited on the ITO coated glass by spin coating at $5000 \mathrm{rpm}$ for 40 seconds followed by baking on hot-plate at $120{ }^{\circ} \mathrm{C}$ for 15 minutes. Alternatively for $n$-i-p cells, $\mathrm{Cs}_{2} \mathrm{CO}_{3}$ is spin coated on ITO coated glass at $4000 \mathrm{rpm}$ for 40 seconds followed by a 15 minute baking on a hot-plate for $150 \mathrm{C}$ in air. This was followed by spin coating of P3HT: $\mathrm{PC}_{60} \mathrm{BM}(1: 1)$ blend solution at $400 \mathrm{rpm}$ for 40 seconds inside the glove-box. This ensured $\sim 200$ $\mathrm{nm}$ of absorber layer. After the deposition, the films are dried slowly inside glove-box. Once the film is dried completely, it was annealed at $160{ }^{\circ} \mathrm{C}$ for 2 minutes followed by $110{ }^{\circ} \mathrm{C}$ for 10 minutes. Finally the metal cathode $(\mathrm{Ca} / \mathrm{Al})$ for $\mathrm{p}-\mathrm{i}-\mathrm{n}$ cell was deposited using thermal evaporation. For the $\mathrm{n}$-i-p cell, $\mathrm{MoO}_{\mathrm{x}}$ was thermally evaporated on the active layer. This is followed by an aluminum deposition using thermal evaporation. All thermal evaporations performed through a shadow mask with a circular aperture with area of $0.106 \mathrm{~cm}^{2}$. More details of fabrication are included in the supplementary material. The supplementary material includes the description of the annealing steps in the various stages of experiment - starting from device fabrication to the post-degradation anneal.

All the thermal treatments were performed on hot plate at above-mentioned temperatures. The fabricated devices were tested inside a nitrogen filled environmental chamber for initial measurement of light IV (current-voltage), dark IV and capacitance spectroscopy. Two solar cells (i.e. metal top contacts) were identified which had similar photovoltaic performance. One of the selected cells was exposed under $2 \mathrm{X}$ intensity $\left(200 \mathrm{~mW} / \mathrm{cm}^{2}\right)$ of the ABET solar simulator that matches the AM 1.5 spectrum of sun, inside the chamber while the rest of the cell area was covered with metal foil to shadow other metal contacts from light exposure. The unexposed contact were used as reference for comparing the effect of photodegradation. Light IV, dark IV, EQE (external quantum efficiency), C-F (capacitance-frequency) were measured on the degraded contact to measure the impact of light soaking on electrical parameters. Finally the entire device were thermally annealed at various temperatures for different times and both the degraded and non-degraded metal contacts were characterized after each thermal annealing step. During the photo exposure the temperature of the device was maintained at room temperature $\left(25^{\circ} \mathrm{C}\right)$ by using a cooling fan, and monitored with a temperature probe.

In this work we utilize the same starting material from a single source, with the same initial concentration of additives and chain terminators for all studies. We then study the role of light in changing the density of defects. $\mathrm{P} 3 \mathrm{HT}: \mathrm{PC}_{60} \mathrm{BM}$ solar cells made with different additives or using different sources do produce somewhat varying solar cell efficiencies due to additives and also are known to accelerate the photo-degradation of the respective cells with the inclusion of additives such as dioiodooctane(DIO) and octane dithiol(ODT) as described in previous publications [25, 26].

It must also be noted that there is a distinct possibility that there can be trace amount of Bromine present as an impurity introduced during the polymerization process which may act as a possible recombination center. There are two previous report which studied the effect of termination of the end 

rather than the conventional H-termination (P3HT-H) [27, 28]. P3HT-Br shows slightly lower light absorption than $\mathrm{P} 3 \mathrm{HT}-\mathrm{H}$, possibly due to the larger size of $\mathrm{Br}$, and altered electrostatic interaction that affects chain packing, and the modified morphology of the P3HT domains. The short circuit current, fill factor, and EQE of P3HT-Br were lower than that of P3HT-H, interpreted by the authors [27] as due to increased charge trapping in P3HT-Br based devices. Photo-degradation has been suggested [27] to lead to increased charge trapping in $\mathrm{P} 3 \mathrm{HT}-\mathrm{Br}$ than $\mathrm{P} 3 \mathrm{HT}-\mathrm{H}$, but further experimental and theoretical studies are required to investigate this effect.

In the present work, the P3HT material used is electronic grade, regio-regular P3HT with average Mw $54,000-75,000$ and PDI $\leq 2.5$. It has a purity of $99.995 \%$ and not expected to have significant amount of impurities such as Br. Impurities and x-ray fluorescence (XRF) of P3HT has been extensively studied by Bannock et al [29]. Their XRF measurements show that Br is only present in the crude P3HT, but acetone washing or chloroform extraction reduces the $\mathrm{Br}$ content to negligible values, which is the case for the P3HT used in these experiments. Furthermore the $\mathrm{MoO}_{\mathrm{x}}$ interlayer we utilize in this paper, prevents the inter-diffusion of $\mathrm{Al}$ from the cathode to the active layer- a mechanism that is independent of the details of the absorber layer. The current work is stressing on the role of mid-gap defect states originating because of prolonged light exposure and their recuperation due to post degradation thermal treatment. Any external treatment both photo and thermal, are unlikely to change that concentration of bromine impurity in the polymer and hence the density of traps contributed by them. We anticipate further work of characterizing bromine content present in the polymer using X-Ray fluorescence technique would yield results similar to those in [29], and to further study the role of deliberate introduction of bromine as an end-cap for polymer on the photo-stability and subsequent recoverability of efficiency.

\section{Need for Thermally Stable Solar Cell Configuration}

In our earlier reported work, [17] we utilized a standard p-i-n solar cell configuration where the active blend matrix was deposited on PEDOT: PSS (the HTL). Holes were collected from bottom ITO/PEDOT: PSS layer while electrons were collected from top $\mathrm{Ca} / \mathrm{Al}$ contact layer. It was reported by $\mathrm{Ma}$ et al [30] that post production annealing at $150{ }^{\circ} \mathrm{C}$ can improve the device efficiency and thermal stability significantly due to temperature induced morphology modification, improved crystallinity, and improved interfaces between the active material and aluminum cathode. We first aimed to confirm that thermal annealing indeed assist the performance recovery of standard p-i-n solar cells as observed by Street et al [16] with no adverse impact of post degradation thermal annealing on device performance in agreement with the observations of by Ma et al [30].

We first degraded an optimized p-i-n cell under 2x solar intensity $\left(200 \mathrm{~mW} / \mathrm{cm}^{2}\right)$ for 48 hours inside the glovebox under $\mathrm{N}_{2}$ flow. The electrical characterization were performed on the degraded contact at each step of experiment namely before exposure, after exposure and after thermal annealing at $100^{\circ} \mathrm{C}$ for 15 min. The light I-V characteristics (Fig 1A/B) show a clear degradation of the IV characteristic with $2 x_{-}$ intensity $\left(200 \mathrm{~mW} / \mathrm{cm}^{2}\right)$ of light soaking, and a partial recovery of the IV characteristic with post degradation annealing (PDA). Fig $1 \mathrm{~A} / \mathrm{B}$ shows that there is a clear improvement in short circuit current after post degradation annealing (PDA). However both FF and Voc degraded further from with the post degradation anneal (PDA). The EQE displayed a similar degradation of $\sim 30 \%$ with light exposure and a partial recovery to $\sim 10 \%$ with post-degradation annealing (PDA) across the wavelength range (400-600 $\mathrm{nm})$. 


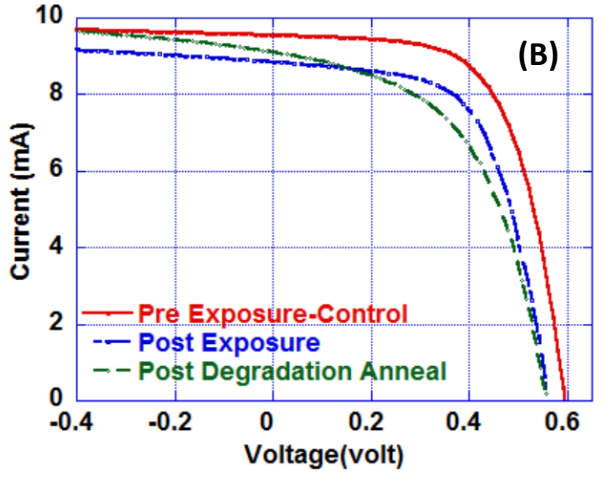

(C)

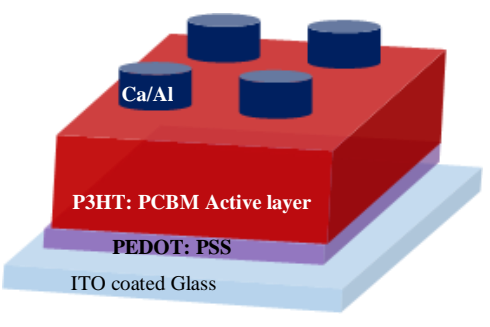

Fig.1. (A)Changes in EQE and (B) light IV of a standard P3HT: PCBM BHJ device after light-degradation (post exposure) with $2 \mathrm{x}$ intensity $\left(200 \mathrm{~mW} / \mathrm{cm}^{2}\right)$ exposure for 48 hours, and post-thermal anneal (PDA) at $100{ }^{\circ} \mathrm{C}$ following the photo-degradation. (C) p-i-n device structure schematic used in this experiment
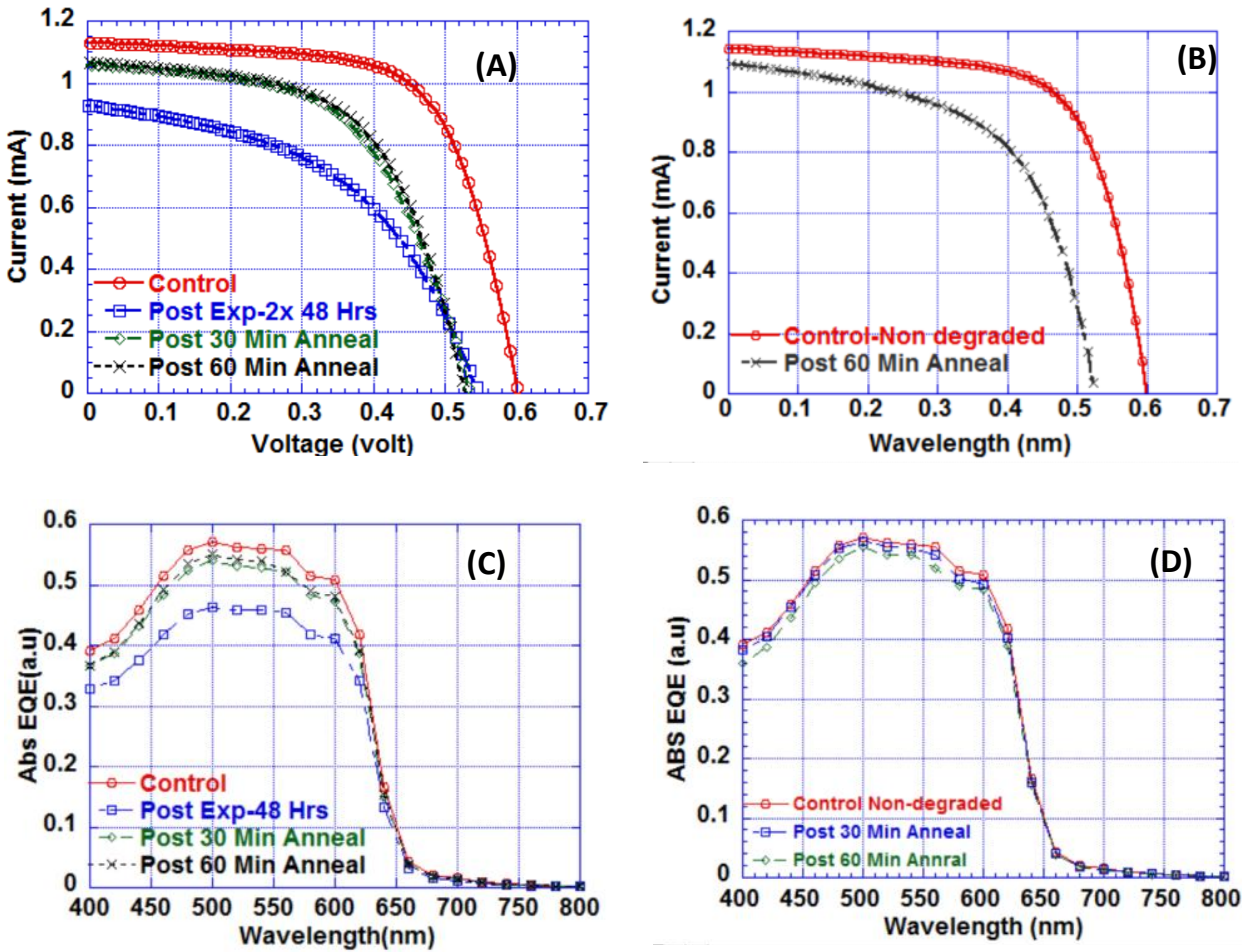

Fig. 2. (A) Light IV of the pristine, light degraded sample after $2 x\left(200 \mathrm{~mW} / \mathrm{cm}^{2}\right)$ exposure, and after 30 minutes and 60 minutes of post degradation-thermal anneal (at $100{ }^{\circ} \mathrm{C}$ ). (B) Light IV of the unexposed contact after different temperature treatments. (C) EQE of the exposed sample after the different temperature treatments. (D) EQE of the unexposed sample after different temperature treatments

The single step post-degradation annealing experiment reveals the promise of partially recovering the photo-degraded performance of the OSC. To investigate this further, an identical OSC was fabricated and exposed to the identical $2 \mathrm{x}\left(200 \mathrm{~mW} / \mathrm{cm}^{2}\right)$ intensity spectrum for 48 hours and then thermally treated multiple times (first at $100{ }^{\circ} \mathrm{C}$ for 30 minute, followed by $100{ }^{\circ} \mathrm{C}$ for 60 minutes). Fig 2 shows the light I$\mathrm{V}$ and EQE measured on a contact degraded under $2 \mathrm{x}\left(200 \mathrm{~mW} / \mathrm{cm}^{2}\right)$ intensity light exposure and another 
identical non-degraded contact in the same device at different stages of the experiment. We observe that thermal annealing tends to recover $\mathrm{I}_{\mathrm{sc}}$ partially but the open circuit voltage $\left(\mathrm{V}_{\mathrm{oc}}\right)$ gets degraded even further after the multistep annealing. Even more interesting is the impact of thermal annealing on the nonphotodegraded contact that was covered during exposure (as described in the experimental details section). It shows that the temperature treatment on the pristine cell i.e. post production annealing (PPA) for the non-degraded contact is detrimental to the performance of solar cell since it reduces $I_{\mathrm{sc}}, \mathrm{V}_{\mathrm{oc}}$ and the fill factor (FF) of the solar cell, contrary to the observation of Ma et al [30]. The unexposed contact shows a $\sim 5 \%$ decrease of $\mathrm{I}_{\mathrm{sc}}$ and $\sim 10 \%$ drop in $\mathrm{V}_{\mathrm{oc}}$ after the thermal treatments (Fig 2B and Fig 2D) respectively.

These findings suggests that two competing mechanisms were simultaneously occurring place during the post degradation annealing steps. The first is the intrinsic degradation of OSC by the thermal treatment during the post-production annealing on the p-i-n cell. The second is the thermal annealing of light-induced defect states at mid-gap of donor-acceptor interface that reduces the SRH recombination leading to better photo-generated charge collection and recovery of short circuit current. Fig 3A shows the partial recovery of mid-gap defect density after the post-degradation annealing (PDA) measured by capacitance spectroscopy while Fig 3B shows the energetic location of mid-gap defect states at the donoracceptor interface. The electronic densities of states (DOS) measurement and data retrieval procedures are discussed in the supplementary material.
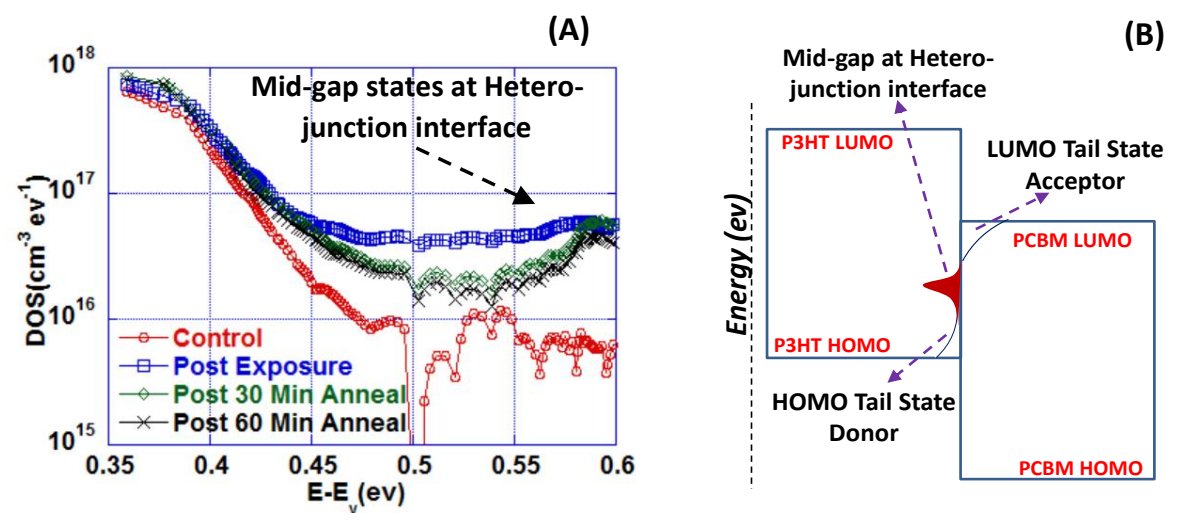

Fig. 3. (A) DOS of the $\left(2 x\left(200 \mathrm{~mW} / \mathrm{cm}^{2}\right)\right.$ Intensity- 48 Hours) exposed contact after different stages of experiment, (B) Schematic showing the location of density of trap states (DOS) at the interface of donor and acceptor (D-A).

We then set out to systematically fabricate a thermally stable OSC that can withstand the post degradation thermal stress, and to characterize and elucidate the nature and dynamics of the recovery. We performed a similar experiment to understand what happens to the photo exposed cells after post degradation annealing at various temperatures. We found from this experiment (Fig 4), that OSCs, when treated thermally even at a lower temperature $\left(75^{\circ} \mathrm{C}\right)$ can show decreased device performance as the annealing progresses. As the annealing temperature increases from $75{ }^{\circ} \mathrm{C}$ to $125{ }^{\circ} \mathrm{C}$, the $\mathrm{V}_{\mathrm{oc}}$, and $\mathrm{FF}$, decrease further with subsequent annealing steps.

The $\mathrm{x}$-axis in Figure 4(A-C) labels the different stages of experiment, as described in the Fig 4D. Post degradation annealing (PDA) shows minor changes in cell electrical parameters for $50{ }^{\circ} \mathrm{C}$. There is a recovery of the $\mathrm{I}_{\mathrm{sc}}$ at the $75^{\circ} \mathrm{C}$ PDA temperature, whereas the $125^{\circ} \mathrm{C}$ anneal decreases $\mathrm{I}_{\mathrm{sc}}$ with further anneal steps. Unlike $\mathrm{I}_{\mathrm{sc}}, \mathrm{V}_{\mathrm{oc}}$ tends to drop almost systematically after each PDA step. This observation supports our previous hypothesis of two competing mechanisms of defect creation and defect annealing 
are occurring simultaneously. Thus eliminating the effect of PDA on interlayer becomes an absolute necessity.
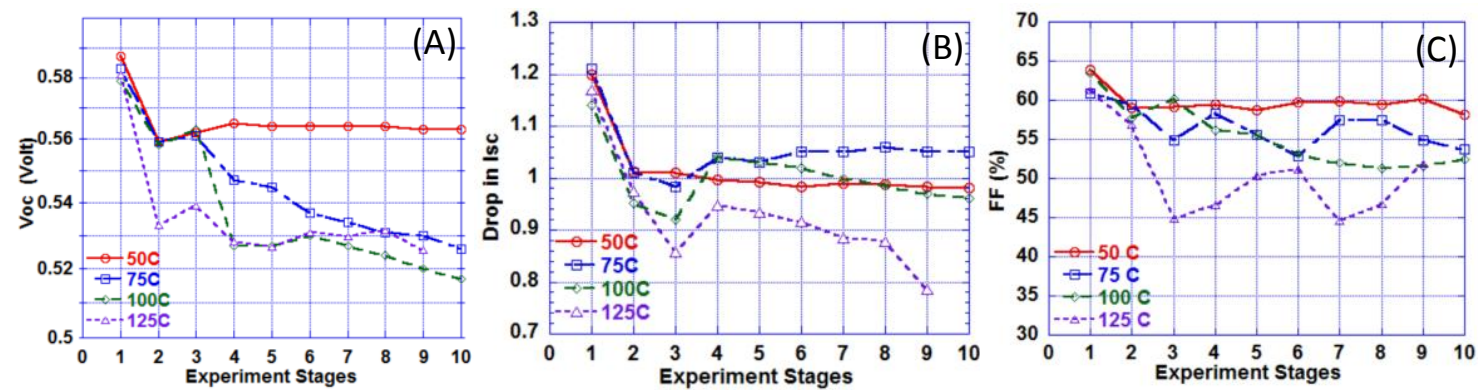

(D)

Fig. 4. (A) Change in $\mathrm{V}_{\mathrm{oc}}$ over different steps of annealing (PPA) for different annealing temperature (B) Change in $\mathrm{I}_{\mathrm{sc}}$ over different steps of annealing (PPA) for different annealing temperature (C) Change in FF over different steps of annealing (PPA) for different annealing temperature,(D) Legend for the different annealing steps utilized.

\section{Thermally stable solar cell for PDA}

Standard p-i-n solar cells: To eliminate the degradation from the PDA treatment, we need a solar cell architecture that is more resistant to the post degradation thermal stresses. We detail the PDA stress on different $\mathrm{p}-\mathrm{i}-\mathrm{n}$ devices in the supplementary material. We found that the metal cathode interlayer plays a significant role in the degradation during PDA since Al, and to a lesser extent $\mathrm{Ca}$, diffuses into the photoactive layer. We also have found that thicker calcium interlayers do not eliminate the metal diffusion and consequent performance degradation of regular pristine $\mathrm{p}-\mathrm{i}-\mathrm{n}$ solar architectures.

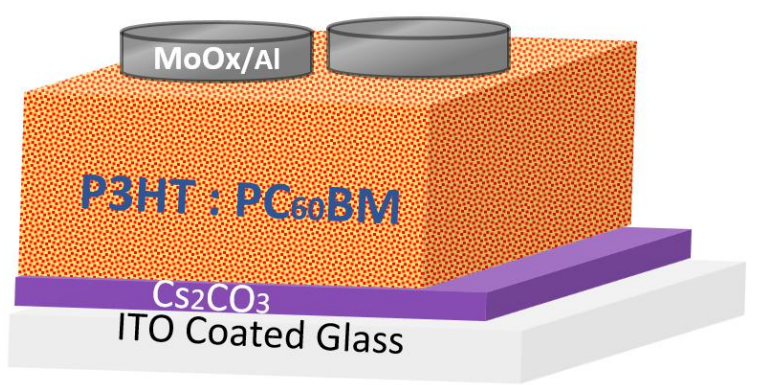

Fig. 5. n-i-p (inverted) Device structure schematic used in this experiment 
Fig. 6. Comparison of Light IV's (A-C) of $\mathrm{MoO}_{\mathrm{x}}$ based inverted n-i-p cells for pristine and after post production annealing for different $\mathrm{MoO}_{\mathrm{x}}$ thickness. (A) $10 \mathrm{~nm}$, (B) $20 \mathrm{~nm}$, (C) $30 \mathrm{~nm}$, (D) Comparison of Light IV of $10 \mathrm{~nm}$ $\mathrm{MoO}_{\mathrm{x}}$ based devices for two different PPA temperature.

We then annealed the $\mathrm{MoO}_{\mathrm{x}}$ film deposited on the active layer before the aluminum deposition. In this experiment, the devices were taken out of the evaporator after deposition of $\mathrm{MoO}_{\mathrm{x}}$ and then treated thermally at different temperature before placing them back in the evaporator for aluminum deposition. It can be seen that the device made with un-annealed (non-treated) $\mathrm{MoO}_{\mathrm{x}}$ (HTL) tend to degrade after thermal treatment of $100{ }^{\circ} \mathrm{C}$ for 15 min during post production annealing (Fig. 7A) (post production annealing $\langle$ PPA $>$ is the thermal anneal step on the device after deposition of Aluminum contact to test the thermal stability of device). Remarkably, when we annealed the device with treated $\mathrm{MoO}_{\mathrm{x}}$ film with similar post production annealing condition, the resulting device shows little or no change in light IV characteristics (Fig 7B). It is worthy to note that the device made with annealed $\mathrm{MoO}_{\mathrm{x}}$ film $(10 \mathrm{~nm} \mathrm{MoO}$ treated with $120{ }^{\circ} \mathrm{C}$ for 10 minute) shows one time reduction in efficiency compared to un-annealed $\mathrm{MoO}_{\mathrm{x}}$ cell. But it shows no degradation thereafter for prolonged annealing steps after deposition of aluminum contact. Clearly the thermal treatment of deposited $\mathrm{MoO}_{\mathrm{x}}$ film before the deposition of 

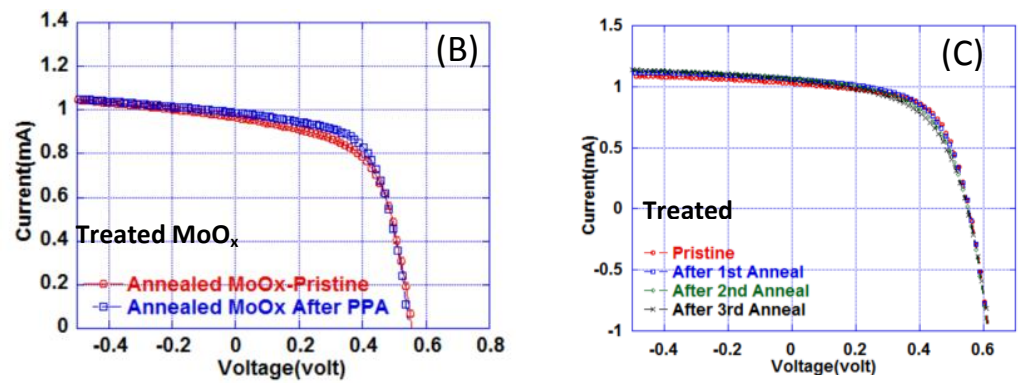

Fig. 7. (A) Change in light IV for un-annealed $\mathrm{MoO}_{\mathrm{x}}(10 \mathrm{~nm})$ based inverted solar cells -both pristine and after PPA $\left(100{ }^{\circ} \mathrm{C}\right.$ for $\left.15 \mathrm{~min}\right)$. (B) Device with treated $\mathrm{MoO}_{\mathrm{x}}\left(10 \mathrm{~nm}-120{ }^{\circ} \mathrm{C}-10 \mathrm{~min}\right)$ - both pristine and after PPA $\left(100{ }^{\circ} \mathrm{C}\right.$ for $15 \mathrm{~min})(\mathrm{C})$ Device with treated $\mathrm{MoO}_{\mathrm{x}}\left(10 \mathrm{~nm}-120^{\circ} \mathrm{C}-10 \mathrm{~min}\right)$ - Pristine and after subsequent PPA steps of $100^{\circ} \mathrm{C}$ for $15 \mathrm{~min}$.

\section{Recovery of thermally stable photo-degraded $n-i-p$ cell by PDA}

After the thermally stable structure with annealed $\mathrm{MoO}_{\mathrm{x}}$ layers were successfully fabricated, the next step was to repeat the photo degradation experiment on the thermally stable architecture. We used 3 different temperatures $\left(70{ }^{\circ} \mathrm{C} / 90{ }^{\circ} \mathrm{C} / 110{ }^{\circ} \mathrm{C}\right)$ for the post-production annealing of 1 hour. The $70{ }^{\circ} \mathrm{C}$ anneal for 1 hour resulting in insignificant recovery of efficiency. We found that the $90{ }^{\circ} \mathrm{C}$ anneal for 1 hour to be lowest optimum temperature for complete recovery of device performance. Figure 8 shows the absolute EQE and light IV for the device under test. 


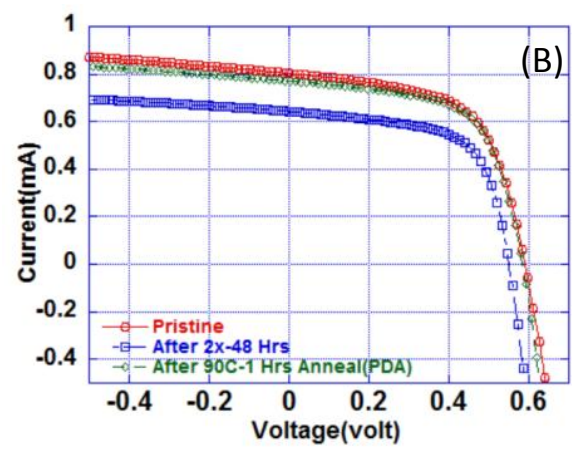

Fig 8. Change in (A) EQE and (B) Light IV at after light exposure of $2 \mathrm{x}\left(200 \mathrm{~mW} / \mathrm{cm}^{2}\right)$ suns for 48 hours, followed by $90{ }^{\circ} \mathrm{C}$ anneal for 1 hour of post degradation anneal (PDA)

The 48 hour $2 \mathrm{x}\left(200 \mathrm{~mW} / \mathrm{cm}^{2}\right)$ light exposure degraded the EQE by $\sim 25 \%$. The post degradation anneal $\left(90{ }^{\circ} \mathrm{C}\right.$ anneal for 1 hour in a $\mathrm{N}_{2}$ environment) then increases the absolute quantum efficiency to almost the value of the pristine non-degraded control sample, at all wavelengths in the 400-630 nm range (Fig. 8 A). The light IV also validated the nearly complete recovery of efficiency of solar cells under test (Fig. 8b). Light exposure produces a decrease in the $\mathrm{I}_{\mathrm{sc}}, \mathrm{FF}$ and $\mathrm{V}_{\mathrm{oc}}$ (Fig. 8b) all of which can be to a significant extent were recovered by post degradation annealing (PDA).

Measurement of the DOS and dark current provided further evidence that, the mid-gap defect states reduced after the PDA with the mid-gap DOS reaching the defect state density of the pristine control sample. The 48 hour 2x-(200 mW/ $\left.\mathrm{cm}^{2}\right)$ exposure increases the mid-gap DOS (Fig. 9A) at all energies. PDA generates a substantial decrease of the mid-gap DOS towards its pristine control value, including complete recovery in the range from $0.5-0.65 \mathrm{eV}$ (Fig. 9A). This validates that the loss mechanism is due to the increase in mid-gap defect states due to photo-degradation, which can be completely recovered by the PDA. Fig. 9B shows an increase in reverse bias dark current with light soaking followed by a partial recovery after the PDA. Due to a high shunt current component in the forward bias dark current, we subtracted the shunt current from the diode current. The subtracted diode current for three different conditions are shown in Fig. 9C which clearly shows the increase in dark forward bias current after light exposure followed by the reduction of the current after PDA treatment. Here we have estimated $I_{0}$ (reverse saturation current- from the dark I-V characteristics). This dark IV correlates well with the reduction in mid-gap defect states found in the DOS measurement (measurement steps and calculation described in supplementary material) (Fig 9A). The integrated DOS in the region between $0.5 \mathrm{eV}$ to 0.65 $\mathrm{eV}$ increased by a factor of $\sim 2.5$ after photo-degradation. Similarly the $\mathrm{I}_{\mathrm{o}}$ estimated from dark current at forward bias is also a factor of 2.5-3 larger for post-degradation sample compared to the control sample, suggesting a strong correlation between DOS and dark current increases, and their subsequent recovery with the PDA treatment. The drop in the reverse bias dark current (Fig 9B) after the PDA treatment indicates a reduction in the interface defect density, which is considered to be the only contributing factor of dark current at reverse bias, by carrier recombination-generation through traps located at the interface of donor and acceptor. 

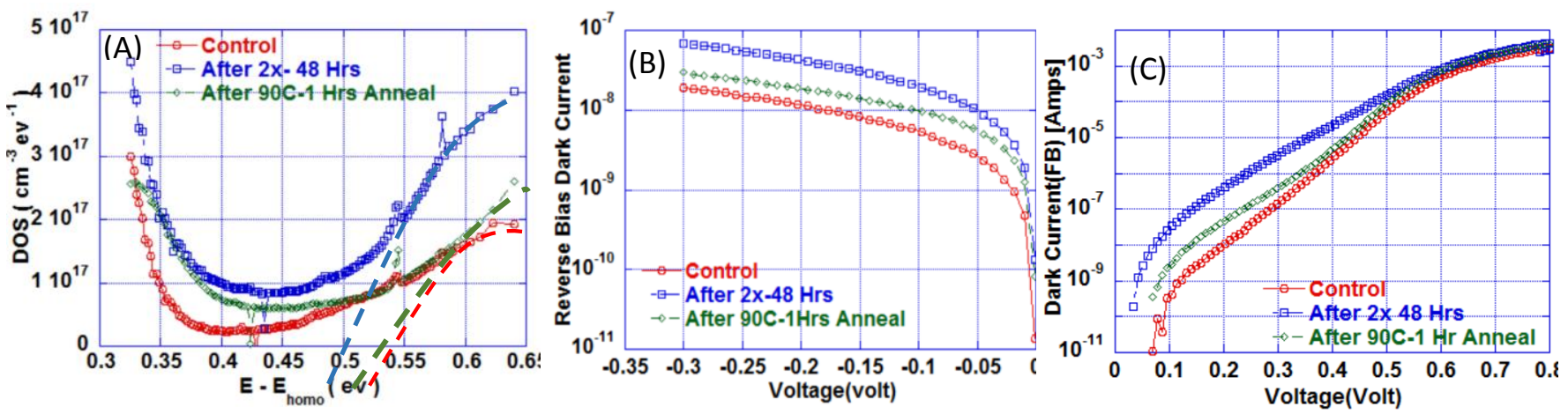

Fig 9. (A) Change DOS distribution at the donor-acceptor (D-A) interface after light exposure of $2 \mathrm{x}\left(200 \mathrm{~mW} / \mathrm{cm}^{2}\right)$ intensity for 48 hours, followed by $90{ }^{\circ} \mathrm{C}$ anneal for 1 hour. (B) Changes in the reverse bias dark current after light exposure of $2 \mathrm{x}\left(200 \mathrm{~mW} / \mathrm{cm}^{2}\right)$ intensity for 48 hours, followed by $90{ }^{\circ} \mathrm{C}$ anneal for 1 hour. (C) Change in forward bias dark current after light exposure of $2 \mathrm{x}\left(200 \mathrm{~mW} / \mathrm{cm}^{2}\right)$ intensity for 48 hours, followed by $90{ }^{\circ} \mathrm{C}$ anneal for 1 hour.

\section{Reversible vs Irreversible degradation}

In our concluding experiment we prepared two identical films of $\mathrm{P} 3 \mathrm{HT}: \mathrm{PC}_{60} \mathrm{BM}(1: 1)$ blends on glass/ITO/PEDOT:PSS substrates substrate and exposed both films under $2 \mathrm{x}\left(200 \mathrm{~mW} / \mathrm{cm}^{2}\right)$ intensity for $\sim 90$ hours. One sample was exposed in inert atmospheric conditions under $\mathrm{N}_{2}$ flow (Fig 10A) while the other identical film was exposed in a chamber filled with oxygen (Fig 10B). Absorbance spectra was measured for the films for the inert atmosphere was measured after degradation and after multiple annealing in the $\mathrm{N}_{2}$ atmosphere (Fig 10A). Similarly the absorbance was measured for an oxygen exposed film at various stages of photo-exposure and after thermal anneal (Fig 10B). It was found that for the film exposed in the nitrogen environment, there are insignificant changes of the wavelength dependent absorption $\mathrm{A}(\lambda)$ after exposure, as well as after multiple annealing. In contrast, the film exposed in the oxygen filled chamber does show very large drops in absorbance likely resulting from permanent rupture of polymer backbone due to oxidation and photo-bleaching. Multiple thermal annealing steps were not able to improve its absorbance spectra indicating that such photo-degradation, or photo-bleaching is an irreversible process occurring in the presence of oxygen. Such irreversible bleaching dynamics are considerably different from the intrinsic photo-degradation in the absence of oxygen which we found are inherently reversible and proposed to be a result of atomic migration within the polymer network. 
Fig. 10. (A) Absorbance study on blend film exposed under $\mathrm{N}_{2}$ for $\sim 90$ Hours and PDA of $100{ }^{\circ} \mathrm{C}$ for 105 min total (B) Absorbance study on blend film exposed under $\mathrm{O}_{2}$ for $\sim 90$ Hours and PDA of $100{ }^{\circ} \mathrm{C}-$ of 1 Hours and 48 hours.

\section{Discussion:}

In this work we reported in detail the results of $90^{\circ} \mathrm{C}$ annealing for 1 hour post degradation annealing PDA. Lower temperatures $\left(70{ }^{\circ} \mathrm{C}\right)$ did not show any significant performance recovery. The same PDA was repeated for $110{ }^{\circ} \mathrm{C}$ and we found that the $110^{\circ} \mathrm{C} / 1$ hour annealing condition tends to follow the same recovery path as the $90{ }^{\circ} \mathrm{C} / 1$ hour sequence. Thus we report the $90{ }^{\circ} \mathrm{C} / 1$ hour condition in the paper, whereas the $110^{\circ} \mathrm{C} / 1$ hour DOS recovery data is included in the supplementary information.

There has been considerable debate about the role of ambient oxygen in photo-degradation of organic solar cells. Like any disordered material, the polymer-fullerene based active layer does have inherent charge trapping centers originating from vacancies, dangling bonds, polymer chain defects, and impurities that are induced during the film preparation. Such charge trapping centers present increased challenge of charge separation at donor-acceptor interface at short circuit conditions as reported previously.[31] In our present work, we concentrate more on the role of light in increasing the interface-defect states energetically located around mid-gap of interface band-gap ( $\mathrm{E}_{\text {LUMO-РсвM }}-\mathrm{E}_{\text {Номо-Рзнт }}$ ) in the absence of ambient oxygen.

However as observed, in our present work we found changes in mid-gap DOS by two orders of magnitude with the degradation in electrical performance in the absence of atmospheric oxygen. This result is in direct agreement with those of Street et al [16] and Bhattacharya et al [17], which show that in the absence of atmospheric oxygen, the electrical property of the device degrades principally due to the evolving density of defect states that generates increased trap-assisted recombination. In this current work we demonstrated that, by using optimal thermal stress on these devices, it is possible to reverse the loss of performance of the organic solar cell caused by photo-degradation. This result suggests that the defect states created at the interface of D-A are metastable in nature. The interpretation underlying these changes arises from density functional theory (DFT) simulations first performed by Northrup [32] and later by Shah et al [33] which found that $\mathrm{H}$ can migrate from the $\alpha-\mathrm{C}$ site of the alkyl chain to the thiophene ring (Fig. 11) which creates a $\mathrm{C}$-dangling bond on $\alpha$-C with a mid-gap defect level, and a $\mathrm{CH}_{2}$ defect within the thiophene ring, and a loss of conjugation in the aromatic backbone. The local H-motion of $\sim 1 \mathrm{~nm}$, requires surmounting an energy barrier of $\sim 3 \mathrm{eV}$ that can be achieved with deep blue or near UV-photons 
in sunlight. The energy barrier for annealing from the defect state to the pristine configuration is substantially lower $(1.5-2 \mathrm{eV})$ and can be surmounted with the thermal treatment such the PDA anneal performed. Since the only local $\mathrm{H}$ motion of $\sim 1 \mathrm{~nm}$ is involved, the entire degradation and recovery process is fully reversible with $\mathrm{H}$ returning back to the original $\alpha-\mathrm{C}$ site. The $\alpha-\mathrm{C}$ is the most reactive $\mathrm{C}$ site, with decreasing reactivity as we traverse further down the alkyl chain. The experimental signature is an increase in mid gap states, consistent with various measurements. The changes in either Raman or infrared absorption are expected to be small since $\mathrm{CH}$ bonds are still formed in the conjugated portion of the structure, and can be an aspect for future high resolution studies. The reversible mid-gap defect generation is analogous to the well-known meta-stability in amorphous hydrogenated silicon (a-Si: $\mathrm{H}$ ) [34], which has also been associated with H-motion. It should be noted that recent DFT calculations [33] indicate that $\mathrm{O}$ can have a different role in oxidizing the aromatic backbone than $\mathrm{H}$ in creating defects.

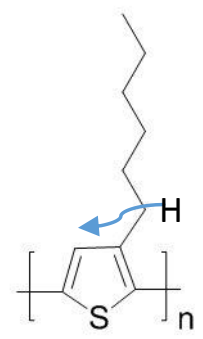

Fig. 11. Schematic depiction of local $\mathrm{H}$ motion from $\alpha-\mathrm{C}$ on the alkyl chain to the thiophene ring in $\mathrm{P} 3 \mathrm{HT}$, creating a dangling bond on $\alpha-\mathrm{C}$ and a $\mathrm{CH}_{2}$ defect within the thiophene group.

We validated our experimental results by repeating the degradation and post degradation annealing procedures on multiple identical samples prepared under similar fabrication condition and all devices showed very similar behavior, showing an increase in dark current as well as reverse saturation current with an proportional increase in mid-gap and interfacial defect states upon photo-degradation and their respective recovery with PDA, showing a strong cross-validation of both measurements.

An important experimental result is the recovery of $\mathrm{V}_{\text {oc }}$ for the annealed $\mathrm{MoO}_{\mathrm{x}}$ layer inverted devices. It is likely that the $\mathrm{MoO}_{\mathrm{x}}$ layer densifies and prevents diffusion of metal through it, preventing degradation of OSC with temperature treatment. This $\mathrm{V}_{\text {oc }}$ recovery could not be achieved in PDA on p-i-n regular device structures shown in Fig $1 \mathrm{~A}$. This is because $\mathrm{Ca} / \mathrm{Al}$ is in direct contact with the organic active matrix which may react and diffuse into the organic active layer, as reported in previous studies [35, 36]. Such metal-organic interaction due to either thermal treatment of light soaking could result in drop of $I_{s c}$ and $\mathrm{V}_{\mathrm{oc}}$ simultaneously. Previous reports validate our initial observation of degradation in $\mathrm{V}_{\mathrm{oc}}$ and $\mathrm{I}_{\mathrm{sc}}$ after thermal treatment of pristine cells as shown in (Fig-2B/D) \& (Fig.-4A/B/C) from inter-layer diffusion into active absorber layer. Thus the phenomena of complete recovery of photo-degradation could not be observed in p-i-n organic regular solar cells as previously shown in (Fig.-1/2) respectively. A paper by Chambon et al [37] on the effect of thermal treatment on the organic-metal interface proposed that with prolonged temperature treatment, metal atom tends to diffuse into the organic active layer which could potentially create charged mid-gap defect states serving as an active recombination center. We have successfully shown that thermal treatment of $\mathrm{MoO}_{\mathrm{x}}$ layer prior to the deposition of $\mathrm{Al}$ metal provides possibly a dense barrier layer between $\mathrm{Al}$ and the organic active layer resulting in improved thermal stability of the OSC, which was essential to demonstrate the reversible nature of light induced mid-gap 

layer interface which provides a thermal stability of the entire cell stack.

Since temperature itself can anneal the photo-degradation of inverted OSCs organic solar cells, it is suggested that an engineered material having very low thermal conductivity with colloidal nano-crystals [38] that absorbs red/infrared wavelengths of the solar spectrum, can potentially be used as a filter layer which can possibly be used to trap heat on the surface of substrate. This can increase the local operating cell temperature and would help in reducing the rate of photo-degradation by the process of selfannealing. Further experimentation in this direction need to be performed. It would be interesting to repeat the experiment of photo degradation with in-situ adjustable temperatures to compare the rate of degradation at different elevated cell temperatures. This can lead us a step closer to the realization of photo-stable plastic photovoltaics.

It is well known that photo-degradation under a $\mathrm{N}_{2}$ atmosphere does not degrade the photo-absorption spectrum of the D-A active matrix, as found by Reese et al [39] and Guerro et al [10]. Similarly it is also reported that photo-degradation of active matrix under oxygen tends to break the polymer backbone resulting in degradation in photo absorption. Furthermore, polymers with bridging $\mathrm{O}$ in $\mathrm{C}-\mathrm{O}-\mathrm{C}$ groups have more degradation pathways due to $\mathrm{O}$ motion, with P3HT being more stable [33]. In our experiment we showed that the oxygen driven photo bleaching permanently resulting in the drop of photo-generation, likely through oxidation of the aromatic backbone. PDA on the photo-bleached sample does not show sign of recovery in photo-generation. Thus photo-bleaching and photo-degradation are characteristically different processes. In the case of photo-bleaching the damage is irreversible and cannot be recovered, while in the other case of photo-degradation, the formation of metastable trap states are reversible leading to complete recovery of performances at optimum PDA condition.

There is a distinct possibility that both prolonged light soaking and (PPA/PDA) can impact the nanomorphology of the donor/acceptor complex. Such change may impact the internal recombination channel and thus can affect the cell performance. We annealed our devices during fabrication up to $110{ }^{\circ} \mathrm{C}$ for 10 minutes and further the device stack was annealed soon after the deposition of $\mathrm{MoO}_{\mathrm{x}}$ film at $120{ }^{\mathrm{O}} \mathrm{C}$ for 10 minutes. Thus we do not anticipate any major change in nano-morphology as all of our reported temperature for PPA or PDA treatments are around that maximum temperature of annealing during fabrication. One quick observation can be made from Fig 10A. It shows that both after light soaking (48 hours) and thermal treatment for a total of $90 \mathrm{~min}$ at $100{ }^{\circ} \mathrm{C}$ under inert atmosphere, no degradation in the characteristics absorption peak can be seen which may indicate that the crystallinity and nanomorphology remains largely stable. Thus we attribute the performance recover of OSC to the recovery of interface defect states. We plan to conduct further experiments to comprehend the change in nanomorphology due to light exposure and prolonged temperature treatment.

\section{Conclusion}

In conclusion we have developed a stable inverted OSC architecture in which light induced degradation of device characteristics can be reversibly annealed by a post degradation anneal (PDA) treatment to their pristine values. The inverted OSCs utilized $\mathrm{MoO}_{\mathrm{x}}$ layers that are annealed immediately after their deposition on the organic layer, and before metal cathode deposition. We presented experimental validation of the formation of metastable defect states in organic solar cell donor-acceptor interface by measuring the change in DOS and dark currents magnitude at reverse bias, upon degradation and their recovery on post deposition anneal. Finally we showed that oxygen driven photo-bleaching is a completely separate degradation mechanism that is inherently different from the photo-degradation in an 
inert atmosphere. Our current work lays the foundation of future degradation studies, and provides a pathway for stabilizing organic solar cells.

This work was supported (in part, R.B.) by the U.S. Department of Energy (DOE), Office of Science, Basic Energy Sciences, Materials Science and Engineering Division. The research was performed at Ames Laboratory, which is operated for the U.S. DOE by Iowa State University under contract \# DEAC02-07CH11358. This work was supported (in part J.B., P.J., V.D.) by a grant from the National Science Foundation (NSF) through grant CBET-1336134).We thank Dr. Mehran Samiee and Max Noack for their thoughtful suggestions and intellectual discussions and especially Max Noack for assistance in setting up the degradation chamber and glovebox.

\section{References:}

[1] J. Zhao, Y. Li, G. Yang, K. Jiang, H. Lin, H. Ade, W. Ma, H. Yan, Efficient organic solar cells processed from hydrocarbon solvents, Nat. Energy 1 (2016) 15027.

[2] Heliatek (Press Release), www.heliatek.com/en/press/press-releases/details/heliatek-sets-new-organicphotovoltaic-world-record-efficiency-of-13-2, accessed (07/03/2016).

[3] F. C. Krebs, K. Norrman, Analysis of the failure mechanism for a stable organic photovoltaic during 10000 h of testing. Prog. Photovolt. 15 (2007) 697-712.

[4] K. Kawano, R. Pacios, D. Poplavskyy, J. Nelson, D.D.C. Bradley, J.R. Durrant, Degradation of organic solar cells due to air exposure, Sol. Energy Mat. Sol. Cells 90 (2006) 3520-3530.

[5] M. Wang, F. Xie, J. Dua, Q. Tang, S. Zheng, Q. Miao, J. Chen, N. Zhao, J.B. Xu, Degradation mechanism of organic solar cells with aluminum cathode, Sol. Energy Mat. Sol. Cells 95 (2011) 33033310.

[6] M.O. Reese, A.J. Morfa, M.S. White, N. Kopidakis, S.E. Shaheen, G. Rumbles, D. S. Ginley, Pathways for the degradation of organic photovoltaic P3HT: PCBM based devices, Sol. Energy Mater. Sol. Cells 92 (2008) 746-752.

[7] M. Jorgensen, K. Norrman, F.C. Krebs, Stability/degradation of polymer solar cells, Sol. Energy Mater. Sol. Cells 92 (2008) 686-714.

[8] A. Seemann, H. J. Egelhaaf, C. J. Brabec, J. A. Hauch, Influence of oxygen on semitransparent organic solar cells with gas permeable electrodes, Org. Electron. 10 (2009) 1424-1428.

[9] M. Manceau, S. Chambon, A. Rivaton, J. L. Gardette. Gardette, S. Guillerezc, N. Lemaître, Effects of long-term UV-visible light irradiation in the absence of oxygen on P3HT and P3HT: PCBM blend. Sol. Energy Mater. Sol. Cells 94 (2010) 1572-1577.

[10] A. Guerrero, P.P. Boix, L.F. Marchesi, T.Ripolles-Sanchis, E.C. Pereira, G.Garcia-Belmonte, Oxygen doping-induced photogeneration loss in P3HT:PCBM solar cells, Sol. Energy Mater. Sol. Cells 100 (2012) 185-191.

[11] F. C. Krebs, Air stable polymer photovoltaics based on a process free from vacuum steps and fullerenes, Sol. Energy Mater. Sol. Cells 92 (2008) 715-726. 
[12] J. Schafferhans, A. Baumann, A. Wagenphahl, C. Deibel, V. Dyakonov, Oxygen doping of P3HT:PCBM blends: influence on trap states, charge carrier mobility and solar cell performance, Org. Electron. 11 (2010) 1693-1700.

[13] F. C. Krebs, Degradation and stability of polymer and organic solar cells, Sol. Energy Mater. Sol. Cells 92 (2008) 685.

[14] A. Rivatona, S. Chambona, M. Manceaua,J-Luc. Gardettea, N. Lemaîtreb, S. Guillerezb, Lightinduced degradation of the active layer of polymer-based solar cells, Polym. Degrad. Stab. 95 (2010) 278-284.

[15] R.A. Street, J. E. Northrup, B. S. Krusor, Radiation induced recombination centers in organic solar cells, Phys. Rev. B 85 (2012) 205211.

[16] R. A. Street, A. Krakaris, S. R. Cowan, Recombination through different types of localized states in organic solar cells, Adv. Funct. Mater 22 (2012) 4608-4619.

[17] J. Bhattacharya, R.W. Mayer, M. Samiee, V.L. Dalal, Photo-induced changes in fundamental properties of organic solar cells, Appl. Phys. Lett. 100 (2012) 193501.

[18] Y. Tamai, H. Ohkita, M. Namatame, K. Marumoto, S. Shimomura, T. Yamanari, S. Ito, LightInduced Degradation Mechanism in Poly(3-hexylthiophene)/Fullerene Blend Solar Cells, Adv. Energy Mater. 6 (2016) 1600171.

[19] T. Yamanari, H. Ogo, T. Taima, J. Sakai, J. Tsukamoto, Y. Yoshida, Photo-degradation and its recovery by thermal annealing in polymer-based organic solar cells, 35th IEEE Photovoltaic Specialists Conference (PVSC) (2010).

[20] E.A. Katz, S. Gevorgyan, M.S. Orynbayev, F.C. Krebs, Out-door testing and long-term stability of plastic solar cells, Eur. Phys. J. Appl. Phys. 36 (2007) 307-311.

[21] T. Tromholt, A. Manor, E. A. Katz, F.C. Krebs, Reversible degradation of inverted organic solar cells by concentrated sunlight, Nanotechnol. 22 (2011) 225401.

[22] Y. Galagan, A. Mescheloff, S.C. Veenstra, R. Andriessena, E.A. Katz, Reversible degradation in ITO-containing organic photovoltaics under concentrated sunlight, Phys. Chem. Chem. Phys. 17 (2015) 3891-3897.

[23] P. Kumar, C. Bilen, K.Feron, X. Zhou, W.J. Belcher, P.C. Dastoor, Enhanced regeneration of degraded polymer solar cells by thermal annealing, Appl. Phys. Lett. 104 (2014) 193905.

[24] M. Prorok, T. Zdanowicz, M. Dusza , F. Granek, Degradation under illumination and partial recovery of performance parameters of the inverted organic solar cells (OPV) based on P3HT:PCBM, 29th European Photovoltaic Solar Energy Conference and Exhibition (2014).

[25] A. Solanki, B. Wu, T. Salim, Y.M. Lam, T.C. Sum, Correlation between blend morphology and recombination dynamics in additive-added P3HT:PCBM solar cells, Phys. Chem. Chem. Phys. 17 (2015) 26111-26120. 

on the Photo stability of P3HT: PCBM Active Layers, J. Phys. Chem. C 119 (2015) 9142-9148.

[27] Y. Kim, S. Cook , J. Kirkpatrick, J. Nelson , J. R. Durrant , D. D. C. Bradley ,M. Giles ,M. Heeney ,R. Hamilton and I. McCulloch, Effect of the End Group of Regio-regular Poly(3-hexylthiophene) Polymers on the Performance of Polymer/Fullerene Solar Cells, J. Phys. Chem. C 111 (2007) 81378141.

[28] J.S. Kim, Y Lee, J.H Lee, J.H Park, J.K Kim, K Cho, High-Efficiency Organic Solar Cells Based on End-Functional-Group-Modified Poly(3-hexylthiophene), Adv. Mater. 22 (2010) 1355-1360.

[29] J H. Bannock, N.D. Treat, M Chabinyc, N Stingelin, M Heeney, and J C. de Mello, The Influence of Polymer Purification on the Efficiency of poly(3-Hexylthiophene):fullerene Organic Solar Cells, Sci. Rep. 6 (2016) 23651.

[30] W. Ma, C. Yang, X. Gong, K. Lee, A.J. Heeger, Thermally stable, efficient polymer solar cells with nanoscale control of the interpenetrating network morphology, Adv. Funct. Mater. 15 (2005) 1617-1622.

[31] S. R. Cowan, W. L. Leong, N. Banerji, G. Dennler, A.J. Heeger, Identifying a Threshold Impurity Level for Organic Solar Cells: Enhanced First-Order Recombination Via Well-Defined $\mathrm{PC}_{84} \mathrm{BM}$ Traps in Organic Bulk Heterojunction Solar Cells, Adv. Funct. Mater 21 (2011) 3083-3092.

[32] J.E. Northrup, Radiation Induced Hydrogen Rearrangement in Poly(3-alkylthiophene), Appl Phys Express 6 (2013) 121601.

[33] S. Shah, R. Biswas, Atomic Pathways Underlying Light-Induced Changes in Organic Solar Cell Materials, J. Phys. Chem. C 119 (2015) 20265-20271.

[34] D. L. Staebler and C. R. Wronski, Reversible Conductivity Changes in Discharge-produced Amorphous Si, Appl. Phys. Lett. 31 (1977) 292-294.

[35] P. Philipp, K.Q. Ngo, J. Kieffer, T. Wirtz; Silver Diffusion in Organic Optoelectronic Devices: Deposition-Related Processes versus Secondary Ion Mass Spectrometry Analysis Artifacts, J. Phys. Chem. C 119 (2015) 23334-23341.

[36] C.M. Zhang, Y.F. Hu, A.W. Tang, Y. Ning, L.F. Lv, F. Teng, The effect of post-annealing on the interface between the aluminum electrode and the active layer in polymer/fullerene solar cells, Appl. Phys. A 117 (2014) 1335.

[37] S. Chambon, L. Derue, M. Lahaye, B. Pavageau, L. Hirsch, G. Wantz, MoO3 Thickness, Thermal Annealing and Solvent Annealing Effects on Inverted and Direct Polymer Photovoltaic Solar Cells, Mater. 5 (2012) 2521-2536.

[38] M. Liu, Y. Ma, R. Y. Wang, Modifying Thermal Transport in Colloidal Nanocrystal Solids with Surface Chemistry, ACS Nano 9 (2015) 12079-12087.

[39] M.O. Reese, A.M. Nardes, B.L. Rupert, R.E. Larsen, D.C. Olson, M.T. Lloyd, S.E. Shaheen, D.S. Ginley, G. Rumbles, N. Kopidakis, Photo induced Degradation of Polymer and Polymer-Fullerene Active Layers: Experiment and Theory, Adv. Funct. Mater. 20 (2010) 3476-3483. 